\title{
Freeze-Thaw and Salt Crystallization Durability of Silica Acid Ester Consolidated Porous Limestone from Hungary
}

\author{
Zita Pápay, Nikoletta Rozgonyi-Boissinot (D) and Ákos Török *(D) \\ Department of Engineering Geology and Geotechnics, Budapest University of Technology and Economics, \\ Múegyetem rkp. 3, 1111 Budapest, Hungary; papay.zita@emk.bme.hu (Z.P.); \\ rozgonyi.boissinot.nikoletta@gmail.com (N.R.-B.) \\ * Correspondence: torok.akos@emk.bme.hu
}

\footnotetext{
check for updates

Citation: Pápay, Z.;

Rozgonyi-Boissinot, N.; Török, Á

Freeze-Thaw and Salt Crystallization Durability of Silica Acid Ester Consolidated Porous Limestone from Hungary. Minerals 2021, 11, 824. https://doi.org/10.3390/min11080824
}

Academic Editor: Fernando Rocha

Received: 13 April 2021

Accepted: 28 July 2021

Published: 29 July 2021

Publisher's Note: MDPI stays neutral with regard to jurisdictional claims in published maps and institutional affiliations.

Copyright: (c) 2021 by the authors. Licensee MDPI, Basel, Switzerland. This article is an open access article distributed under the terms and conditions of the Creative Commons Attribution (CC BY) license (https:// creativecommons.org/licenses/by/ $4.0 /)$.
Abstract: The durability of consolidated highly porous limestones was tested after salt and freezethaw cycles. Three porous limestone lithotypes that were commonly used in construction in the Central-European region during previous centuries were selected for the tests. Specimens of Miocene limestone were consolidated with four different types of ethyl silica-based consolidants (KSE 100, KSE 300, KSE 300 E, KSE 300 HV). After consolidation, the samples were exposed to freeze thaw cycles and salt crystallization tests. Water saturation under atmospherically pressure, capillary water absorption and splitting tensile strength were measured on treated and untreated samples to assess change attributed to consolidation in the open porosity and mechanical parameters. The increase in the tensile strength of the medium-grained samples was higher than that of the consolidated fine-grained lithotypes. The effect of consolidation treatment was very different in terms of poresize distribution as obtained by Mercury intrusion porosimetry (MIP). Untreated and consolidated samples were subjected to 10 cycles of sodium sulphate crystallization (EN 12370) and 10 freeze-thaw cycles (EN 12371) tests. Experiments concluded that in addition to the initial strength increase after the conservation, the modified pore structure is the crucial factor to evaluate the long-term efficiency of stone conservation.

Keywords: consolidation; durability; capillarity; tensile strength; porous limestone

\section{Introduction}

The consolidation of porous weathering-sensitive stones is very common in restoration practice. Despite the short-term strengthening effect of consolidants, several properties of the stones change. The disadvantages of these treatments only appear in the long term. The current paper provides additional information on the durability and long-term behavior of consolidated porous limestone using laboratory tests to assess the ethyl-silicate treated specimens' mechanical properties and the limestone's textural changes. It focuses on the testing of low durable stone, a porous Miocene limestone. Many emblematic buildings were built with this porous limestone in Hungary; specifically, the House of Parliament, Mathias Church [1], and the Citadella [2] in Budapest; or the Church of Zsámbék [3] and the Church of Ják [4] in the countryside. Similar Miocene limestone types are also known from other central European countries such as Austria and Slovakia [5], and the Czech Republic $[4,6,7]$. Other occurrences of porous limestone with similar properties were also reported from Belgium [8], Malta [9], Italy [10], and France [11,12].

Facades built from these stone types currently show variable weathering forms due to physical, chemical, or complex processes. The physical properties and long-term behavior of porous stones can be addressed in two different ways. On the one hand, the mechanical parameters, the mineralogical composition and the micro-fabric can be rapidly assessed under laboratory conditions. On the other hand, weathering experiments allow for the assessment of the long-term durability of stones. 
From the durability point of view, water absorption, freeze-thaw durability and resistance to salt crystallization are the key properties that influence the long-term behavior of porous stones. It has been documented that porosity is one of the key factors of limestone durability [13]. Additionally, water saturation and water absorption can significantly modify the behavior of porous stones, especially porous limestone [14,15]. Water and frost can also influence the behavior of porous rocks [16] and rock masses [17].

Salt crystallization causes significant damage in stones, especially porous tuffs and limestone [18-20]. The relationship between the pore structure and salt weathering has been investigated by [21]. They examined the pore system of several different sedimentary rocks (limestone, sandstone, dolostone, and travertine), testing water absorption and water vapor transfer, and determined the pore distribution with mercury intrusion porosimetry. The tested limestones from the Miocene had high open porosity. The combination of salt and freeze-thaw were studied by [22] on sandstones, limestones, dolostones, and travertine. In addition to aesthetic problems, weathering processes cause loss in stone strength (Figure 1).
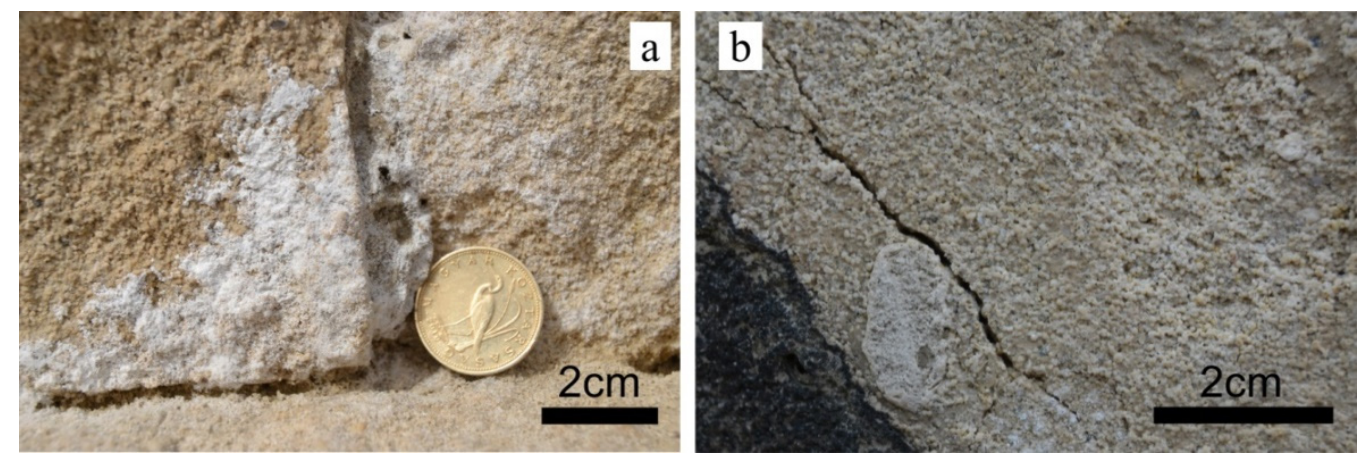

Figure 1. Decay in porous limestone due to salt crystallization (a) and due to frost (b).

For strengthening pore structure, commercially available ethyl silicate agents are commonly used for deteriorated stones in the protection of historic buildings. After the renovation, consolidated parts of the building are also exposed to frost and salt load. Consolidation is believed to strengthen the stone and makes it more resistant and durable. A key issue for the long-term success of conservation is how weathering processes affect conserved stone. The compatibility of consolidants and porous limestone is discussed in [23]. In that paper, St. Margarethen Limestone was examined, which is very similar to the one lithotype from Fertőrákos of our investigations. Leitha limestone (from St. Margarethen) and sandstone were studied by [23] with three different consolidants (tetraethyl-orthosilicate in isopropanol with nano- $\mathrm{TiO}_{2}$, alkyl-trialkoxysilane in isopropanol with $\mathrm{TiO}_{2}$ and a solvent-free tetraethyl-orthosilicate). Before treatment, micro-cracks were formed due to heating. They compared the properties of the artificially aged and subsequently treated specimens with the untreated artificially aged and untreated sound specimens. Studying fewer stone varieties, previous research has investigated the effect of some consolidants and tested the treatment process (consolidants uptake, time of consolidation). Ruffolo et al. investigated the effect of consolidation (nanoLime, tetra-ethyl silicate) on one Italian limestone with high porosity (27 V\%) [24]. The samples were first subjected to sodium sulfate crystallization followed by consolidation. Subsequently, the salt crystallization tests were repeated. Karatasios et al. investigated the effect of tetra-ethyl silicates and water repellent products on the water transport properties of marly limestone [25]. In our test, we used silica acid esters. The selection of the four tested materials is justified since these are the most commonly used consolidants in Hungary and commonly applied worldwide [26] for stones other than limestone, such as sandstone [27,28] or volcanic tuffs [29]. For limestone, silica acid esters are also used but in recent years, studies dealing with nano-lime treatment are also known [30-32]. Another type of porous carbonate is travertine. This lithotype is more durable and less sensitive to freeze-thaw damage [33-36] than the tested Miocene porous limestone [16], and it has been widely 
used as a replacement stone in Hungary [33,37]. However, the consolidation of this stone type is not a common practice in Central Europe.

The current paper aims to demonstrate porous stones' durability after consolidation with a laboratory testing of a Miocene limestone. Four silica acid esters consolidants with different gel deposition rates and solvent contents were applied. Accelerated weathering tests of frost and salt crystallization were used to assess the efficacy of consolidation. Using the example of three types of porous lithotypes, the paper demonstrates that the increase of strength parameters is not necessarily a good indicator of durability after consolidation.

\section{Materials and Methods}

Laboratory tests were performed on three different types of porous limestone collected from two locations in Hungary (Figure 2). A fine- (SF, Figure 3a) and a medium-grained (SM, Figure 3b) limestone from Sóskút and a medium-grained limestone from Fertőrákos (FR) were used in the conservation trials (Figure 3c).

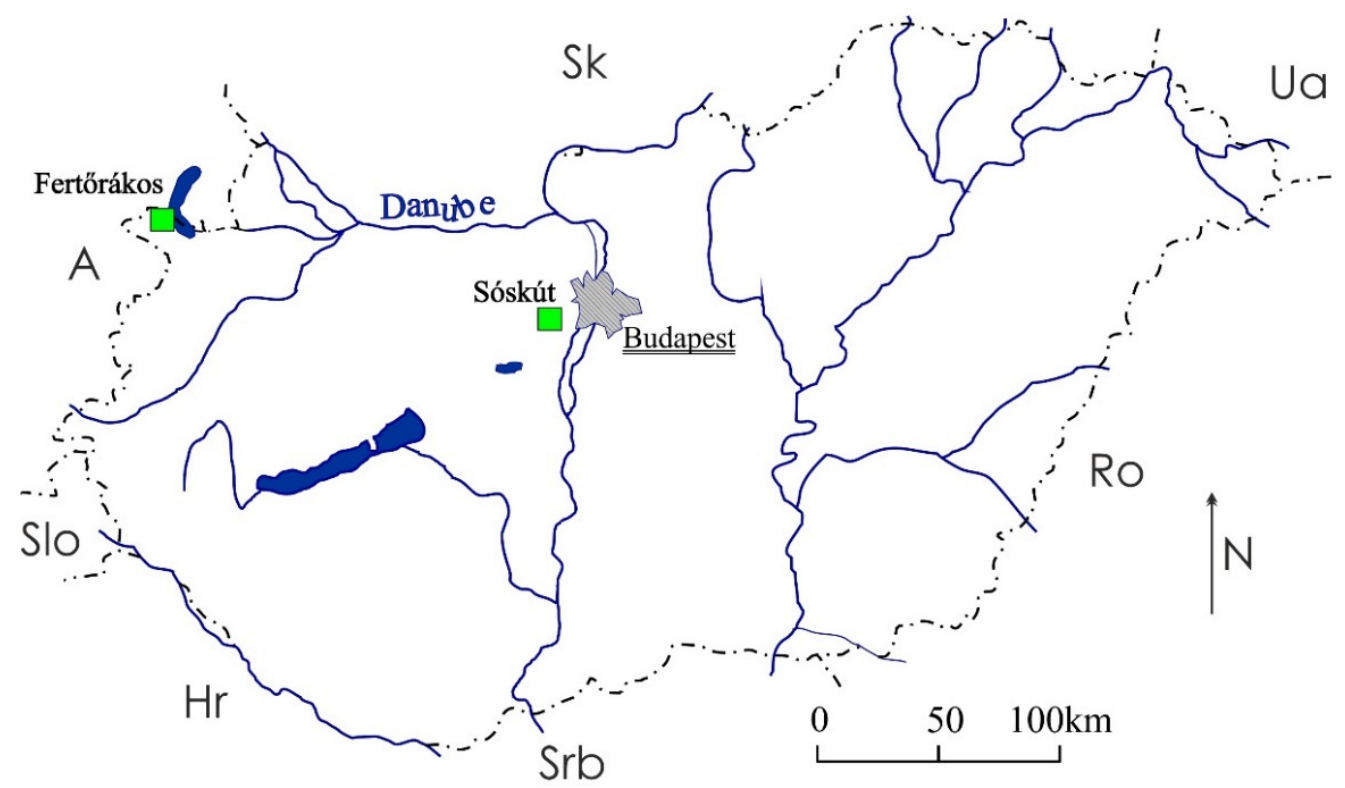

Figure 2. Locations of the limestone quarries, Fertőrákos and Sóskút (marked in green squares).

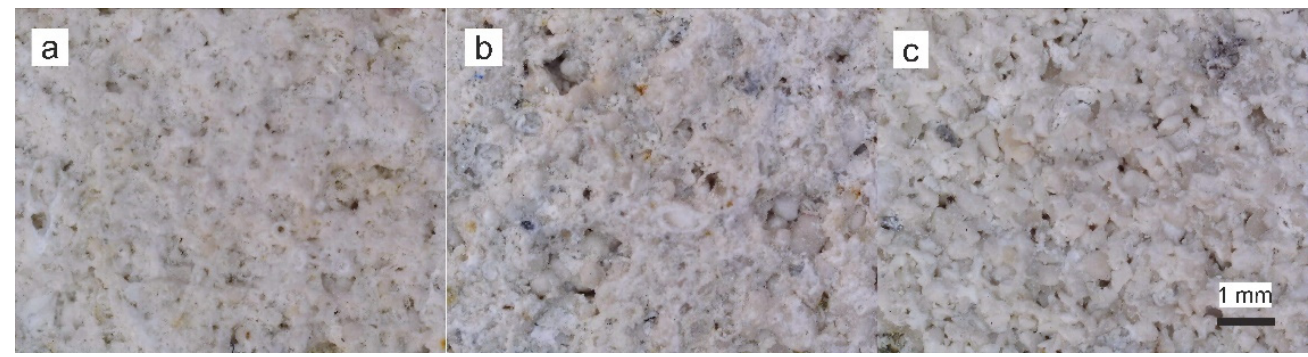

Figure 3. Micro-fabric of tested porous limestone, (a)—fine-grained limestone from Sóskút (SF); (b)— medium-grained limestone from Sóskút (SM); (c)—medium-grained limestone from Fertőrákos (FR).

The Leitha limestone quarry in Fertőrákos is located in the northwest part of Hungary (Figure 2). The same rock can be found on the other side of the Hungarian-Austrian border, in Sankt Margarethen. The stone material of the building blocks of Votivkirche, the town hall, the Kunsthistorisches Museum and the University of Vienna also come from this region. The Leitha limestone is mainly a biogenic Miocene sediment from the Badenian age. It was built from calcareous algae and molluscs, and consists of red algae (Lithothamnium), but it also contains macrofossils such as the fragments of mussels and sea urchins. 
The limestone from Sóskút was also formed during the Miocene period. It is a younger stone than the Leitha limestone. This stone was deposited during the Sarmatian period, and it is varied widely from the fine-grained to the coarse-pored structure. The coarse-pored rock structure results from the appearance of numerous oolite grains and shell fragments. The quality of the stone as a building stone varies from not frost-resistant to frost-resistant, and depends on the pore structure and the proportion of fossils. The higher quality and frost resistant varieties are not available anymore since the resources are exhausted. In this study, therefore, two lower quality lithotypes were investigated that were available from the two localities mentioned above: fine-grained and medium-grained (Figure 3) limestones.

Four different ethyl silicate-based consolidants were applied in the tests (supplier: Remmers Baustofftechnik GmbH Löningen, Germany) (Figure 4).

\begin{tabular}{|c|c|c|c|c|}
\hline $\begin{array}{l}\text { Macro image of consolidants } \\
\text { after polymerization }\end{array}$ & & & & $\rightarrow z^{2}$ \\
\hline Commercial name & KSE 100 & KSE 300 & KSE $300 \mathrm{E}$ & KSE $300 \mathrm{HV}$ \\
\hline $\begin{array}{l}\text { Active ingredient } \\
\text { content (approx.) })^{*}\end{array}$ & $20 \%$ & $99 \%$ & $50 \%$ & $98 \%$ \\
\hline $\begin{array}{l}\text { Gel deposit rate } \\
\text { (approx. by mass)* }\end{array}$ & $10 \%$ & $30 \%$ & $30 \%$ & $30 \%$ \\
\hline Density $\left(20^{\circ} \mathrm{C} ; \mathrm{g} / \mathrm{cm}^{3}\right)^{\star *}$ & 0.79 & 0.98 & 0.90 & 0.99 \\
\hline Viscosity (kinematic at $20^{\circ} \mathrm{C} ; \mathrm{s}$ ) & 11 & 12 & 11 & 12 \\
\hline Organic solvents ${ }^{\star \star}$ & $80 \%$ & $0.4 \%$ & $49.3 \%$ & solvent-free \\
\hline
\end{tabular}

Figure 4. Consolidate agent properties according to the manufacturer ${ }^{*}$ data from Remmers technical datasheets; $^{* *}$ data from Safety data sheet).

KSE 100 and KSE 300 are simple stone consolidants containing tetraethyl orthosilicate in different dilution. In the meantime, KSE 300E is an elastic stone consolidant, while KSE $300 \mathrm{HV}$ contains a special bonding agent that provides better adhesion with calcite. KSE 100 has a lower gel deposition rate (10\%) than the other 3 materials (Table 1, Figure 4).

Table 1. Composition of the tested consolidants according to safety data sheets from producer (Remmers Gmbh).

\begin{tabular}{cccc}
\hline KSE 100 & KSE 300 & KSE 300E & KSE 300 HV \\
\hline Hydrocarbons, C11-C12, & Tetraethyl & Ethanol & Tetraethyl \\
isoalkanes, $<2 \%$ aromatics & orthosilicate & $40-60 \%$ & orthosilicate \\
$60-80 \%$ & $60-80 \%$ & Tetraethyl orthosilicate & \\
Hydrocarbons, C12-15 & & $5-10 \%$ & \\
$20-40 \%$ & & \\
Tetraethyl orthosilicate & & & \\
$\geq 5-<10 \%$ & & & \\
\hline
\end{tabular}

Cylindrical specimens of $54 \mathrm{~mm}$ diameter and $26 \mathrm{~mm}$ or $54 \mathrm{~mm}$ of height were drilled from limestone blocks. The specimens were treated with ethyl silicate by full immersion in consolidating agents for $10 \mathrm{~min}$ under laboratory conditions. Capillary water absorption (EN 1925) was performed on samples with $54 \mathrm{~mm}$ height to assess the porosity characteristics of untreated and consolidated limestones. Because of the initial hydrophobic effect of the consolidants, capillary water absorption was measured one year after consolidation. Mercury intrusion porosimetry (MIP) was applied on untreated and treated samples to represent the pore-size distribution and its change due to consolidation. On samples with $26 \mathrm{~mm}$ height, full water saturation (EN 13755) was performed and these specimens were subjected to sodium sulphate crystallization (EN 12370) and freeze-thaw tests (modified EN 12371) to assess durability. Salt crystallization test was performed with 
$14 \mathrm{~m} / \mathrm{m} \%$ of $\mathrm{Na}_{2} \mathrm{SO}_{4} \cdot 10 \mathrm{H}_{2} \mathrm{O}$ solution. Samples were immersed in the solution for $2 \mathrm{~h}$. After they gradually dried at $105^{\circ} \mathrm{C}$ for $10 \mathrm{~h}$, they finally cooled down to room temperature in $2 \mathrm{~h}$. In every cycle, the weight loss of samples was recorded. In total, 10 freeze-thaw cycles were performed where one cycle made up $4 \mathrm{~h}$ of freeze and $4 \mathrm{~h}$ of thaw. Specimens were fully saturated in water and were frozen at $-20^{\circ} \mathrm{C}$. To assess the effect of consolidation and freezing on strength, splitting tensile strength was determined according to ASTM D3965 on air dry and aged-treated/untreated samples (Table 2). Selected samples were analyzed using SEM (JSM-6610 LV scanning electron microscope, JEOL, Tokyo, Japan) to visualize the consolidants in the pores.

Table 2. Experimental methods and number of samples.

\begin{tabular}{ccccc}
\hline \multirow{2}{*}{ Method } & \multirow{2}{*}{ Standard } & \multicolumn{3}{c}{ Number of Samples } \\
\cline { 3 - 4 } & & SF & SM & FR \\
\hline Water saturation & EN 13755 & 30 & 30 & 15 \\
Capillary water absorption & EN 1925 & 10 & 10 & - \\
Sodium sulphate crystallisation & EN 12370 & 30 & 30 & 15 \\
Freeze-thaw durability & EN 12371 (modified) & 30 & 30 & 15 \\
Splitting tensile strength & ASTM D3965 & 90 & 90 & 45 \\
\hline
\end{tabular}

\section{Results}

\subsection{Material Properties}

The fine-grained type (SF) is the most porous one with MIP porosities of $29 \%$, while the medium-grained oolitic limestone type (SM) has a mean porosity value of $20 \%$. Meanwhile, Fertórákos limestone (FR) has a porosity between these two former ones (23\%).

The open pores spaces were reduced after consolidation, leading to a weight increase. The weight change of consolidated samples are summarized in Table 3. On the one hand, a small amount of KSE 100 was found in the pores of SF and SM limestone 2.20 and $1.24 \%$, respectively. On the other hand, the highest volume of consolidants is linked to the consolidation with KSE $300 \mathrm{HV}$. The smallest amount of KSE $300 \mathrm{HV}$ is in medium-grained limestone (SM) where $2.41 \%$ was measured, which is nearly half of the proportion found in SF. Similar to KSE $300 \mathrm{HV}$, a relatively high amount of KSE 300E was measured in SF and SM. In comparison, it seems that KSE 300 also occupied a few per cent of pores, but its proportion is less than that of the KSE $300 \mathrm{E}$ and KSE $300 \mathrm{HV}$. In summary, the least amount of consolidants was found in the pores of SM (Table 3).

Table 3. Weight change of the limestones due to consolidation ( $w / w \%)$ (standard deviation of measured data is in brackets).

\begin{tabular}{ccccc}
\hline Limestone & KSE 100 & KSE 300 & KSE 300 E & KSE 300 HV \\
\hline SF & $2.20(0.10)$ & $3.56(0.20)$ & $4.32(0.14)$ & $4.87(0.22)$ \\
SM & $1.24(0.16)$ & $2.26(0.13)$ & $2.29(0.29)$ & $2.41(0.28)$ \\
FR & & $3.24(0.12)$ & & $4.57(0.28)$ \\
\hline
\end{tabular}

The results of capillary water absorption tests indicate that there are significant differences in the pore-size distribution of the tested porous limestones. The comparative results of the reference samples and samples after consolidation are given in Figures 5 and 6 . The fine-grained limestone (SF) absorbed the highest amount of water (27 V\%, Figure 5) while the medium-grained one (SM) had a lower capillary water absorption (17 V\%, Figure 6). The fastest water uptake was observed at medium-grained limestone (SM) with KSE 100 treated samples. With KSE 300E treated medium- (SM) or fine-grained limestone (SF) did not absorb any water by capillarity, meaning that the pores were partly occluded by the consolidants. 


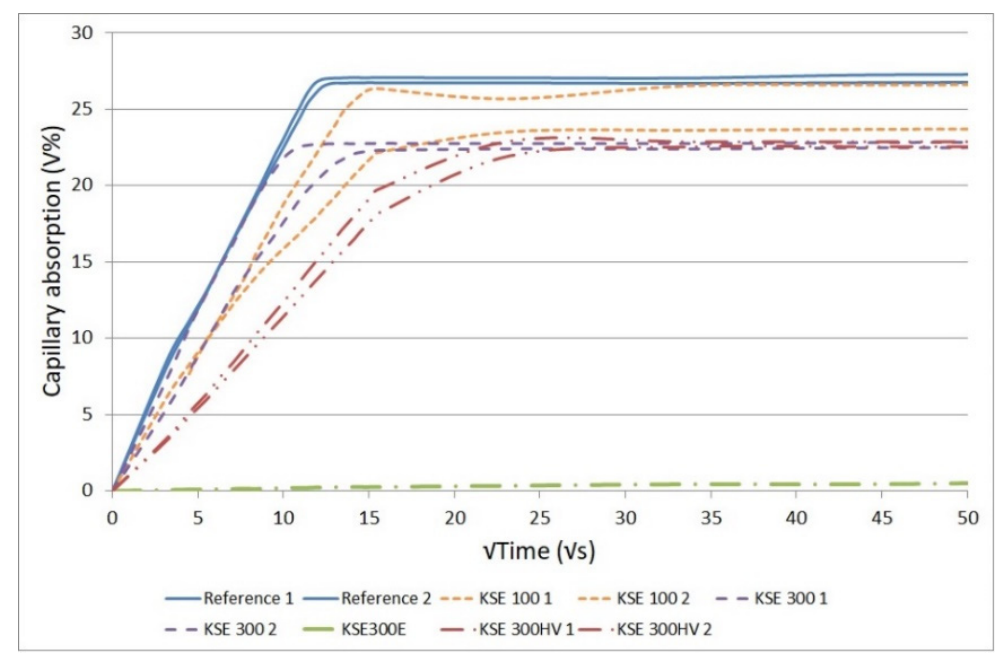

Figure 5. Capillary water absorption in untreated and consolidated fine-grained limestone from Sóskút (SF).

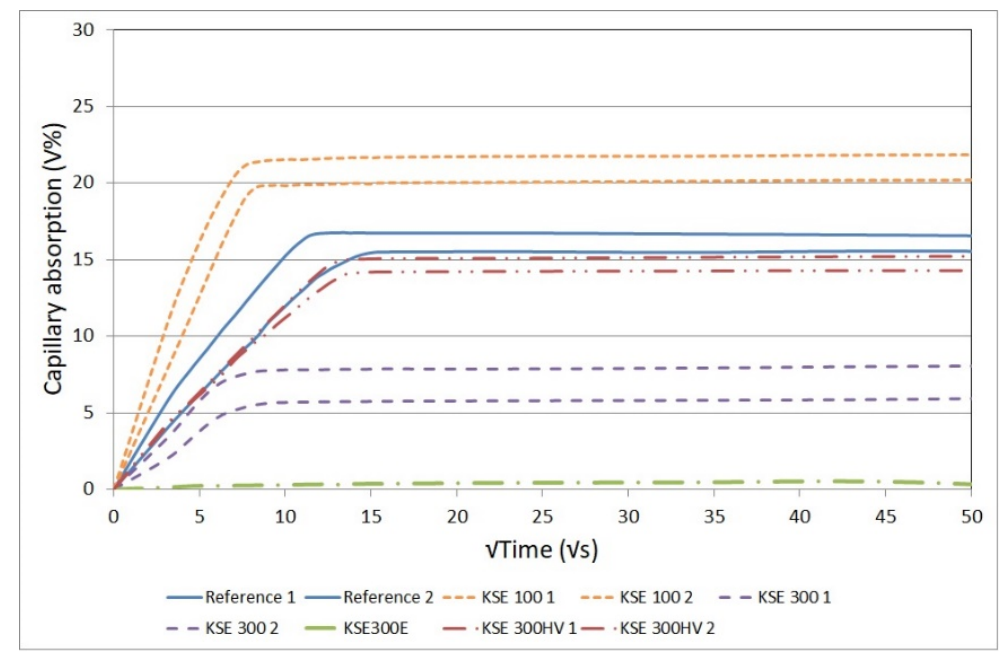

Figure 6. Capillary water absorption in untreated and consolidated medium-grained limestone from Sóskút (SM).

The mercury intrusion porosimetry tests suggest that major changes in pore size distribution took place at fine-grained porous limestone of Sóskút (SF) which was treated with KSE $300 \mathrm{HV}$ (Table 4). More specifically, the proportion of pores with a diameter of $10-63 \mu \mathrm{m}$ decreased with a parallel increase in the proportion of pore ranges of $0.1-10 \mu \mathrm{m}$ (Table 4). The same trend with a lower rate of change was observed at KSE $300 \mathrm{HV}$ treated medium-grained porous limestone (Figure 7). The consolidants of KSE 100 and KSE 300 also modified the pore-size distribution of medium-grained porous limestone of Sóskút (SM). In both cases, the proportion of pores of 10-63 $\mu \mathrm{m}$ increased, while the pores of 0.1-10 $\mu \mathrm{m}$ decreased (Table 4). The porous limestone of Fertórákos (FR) display different trends in pore-size distribution due to consolidation. There is a slight decrease in pores of 10-63 $\mu \mathrm{m}$, while after consolidation, the proportion of pores of $0.1-10 \mu \mathrm{m}$ increased (Table 4). Otherwise, the trend in pore size distribution is similar in the reference samples and consolidated ones (Figure 7). 


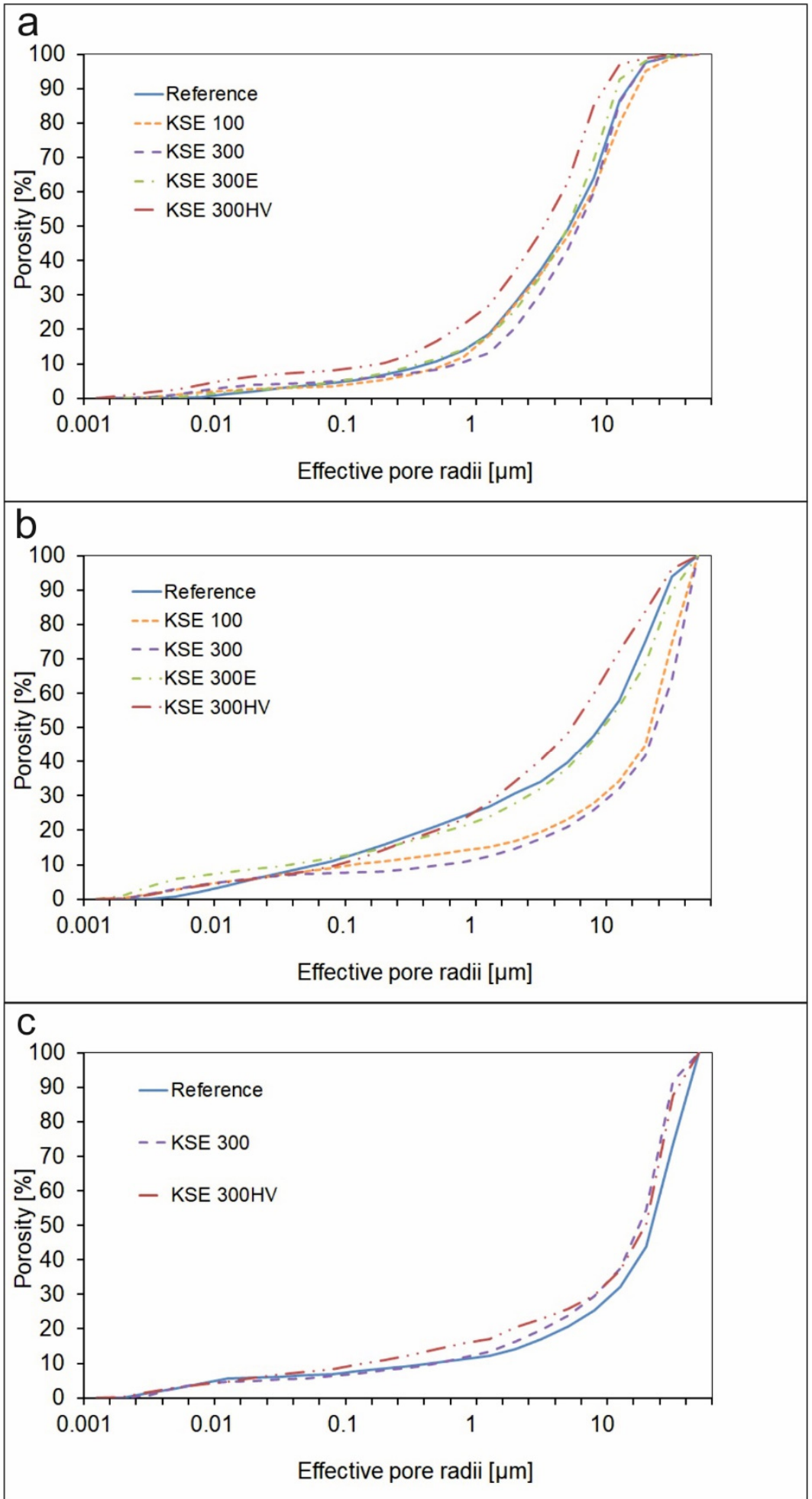

Figure 7. Pore size distribution in untreated samples and change of pore size distribution due to consolidation: (a) SF; (b) SM; (c) FR. 
Table 4. Results of the MIP on untreated and treated samples.

\begin{tabular}{cccccc}
\hline \multirow{2}{*}{ Limestone } & $\begin{array}{c}\text { Hg-Effective } \\
\text { Porosity (V\%) }\end{array}$ & $\begin{array}{c}\mathbf{1 0 - 6 3} \boldsymbol{\mu m} \\
\mathbf{( \% )}\end{array}$ & $\begin{array}{c}\mathbf{0 . 1 - 1 0} \boldsymbol{\mu m} \\
\mathbf{( \% )}\end{array}$ & $\begin{array}{c}<\mathbf{0 . 1} \boldsymbol{\mu m} \\
\mathbf{( \% )}\end{array}$ \\
\hline \multirow{6}{*}{ SF } & Reference & 29.32 & 35.83 & 59.84 & 4.32 \\
& KSE 100 & 29.36 & 38.99 & 57.47 & 3.54 \\
& KSE 300 & 27.74 & 40.05 & 54.98 & 4.96 \\
& KSE 300E & 27.06 & 30.59 & 64.74 & 4.69 \\
& KSE300HV & 25.42 & 14.70 & 77.31 & 7.99 \\
\hline \multirow{6}{*}{ SM } & Reference & 20.45 & 52.56 & 36.36 & 11.09 \\
& KSE 100 & 21.35 & 72.11 & 18.82 & 9.06 \\
& KSE 300 & 21.07 & 74.20 & 18.18 & 7.60 \\
& KSE 300E & 20.19 & 53.44 & 34.65 & 11.91 \\
& KSE300HV & 18.24 & 40.42 & 49.98 & 9.61 \\
\hline \multirow{3}{*}{ FR } & Reference & 23.36 & 74.66 & 18.40 & 6.95 \\
& KSE 300 & 21.68 & 70.54 & 23.08 & 6.36 \\
& KSE300HV & 22.03 & 70.20 & 21.40 & 8.42 \\
\hline
\end{tabular}

The SEM images of the consolidated samples clearly demonstrate the different properties of consolidants in terms of gel formation and solid structure. KSE 100 forms 100 micrometer-scale thin plates in the pores (Figure 8a,b). Compared to KSE 100, the silica gel of KSE 300 has thicker and visibly stronger bonds between carbonate particles of the limestone (Figure 8c,d). From all tested consolidants, KSE 300 E forms the thinnest flakes but it penetrated into the smallest pores forming elastic bonds between carbonate particles (Figure 8e,f). KSE $300 \mathrm{HV}$ caused the largest weight increase (Table 3) filling the pores but not entirely occluded open pore spaces (Figure 8g,h).

Tensile strength tests provided important information on the durability of the tested porous limestone types. All presented values are the average of at least five tests. The lowest tensile strength was measured on fine-grained limestone under laboratory conditions (mean value: $1.03 \mathrm{MPa}$ ), and the highest strength was recorded on Fertórákos limestone (mean value: $2.04 \mathrm{MPa}$ ). At the same time, the indirect tensile strength of medium-grained limestone was 1.38 MPa under laboratory conditions (Figure 9).

The increase of tensile strength due to consolidation was not uniform (Table 5). The consolidants had very different effects on the lithotypes' strength. KSE 300 increased the strength of most of the limestones from Sóskút (SF and SM), while KSE100 had the smallest effect (Figure 9).

The highest increase in strength was measured on the medium-grained limestone from Sóskút (SM). The mean values of the tensile strength of these samples increased by 61 percent after treatment with KSE 300. Almost the same increase in values was measured on the samples after treatment with KSE 300E and KSE $300 \mathrm{HV}+49 \%$ and $+48 \%$, respectively. The strength changes were the smallest in the fine-grained oolitic limestone with a small increase of $9 \%$ after consolidation with KSE 300E, and 11\% after the consolidation with KSE 100. The KSE 300 consolidant was proved to be the most effective also for SF; an increase of $+53 \%$ was measured. Consolidation with KSE 300 HV increased the strength only by $21 \%$.

From the Leitha limestone (FR) there were not enough samples available for the four treatments, thus only two types of consolidants were tested (KSE 300 and KSE $300 \mathrm{HV}$ ). Contrary to SF and SM, for the FR limestone, it was not the KSE 300 that resulted in the highest strength augmentation. KSE $300 \mathrm{HV}$ proved to be the most effective for FR limestone, with a $37 \%$ increase in strength, while KSE 300 caused a rise in the strength with $20 \%$ (Table 5). 
Table 5. Change in tensile strength after consolidation (ratio of consolidated and unconsolidated tensile strength).

\begin{tabular}{ccccc}
\hline Limestone & KSE 100 & KSE 300 & KSE 300 E & KSE 300 HV \\
\hline SF & 1.11 & 1.53 & 1.09 & 1.21 \\
SM & 1.30 & 1.61 & 1.49 & 1.48 \\
FR & & 1.20 & & 1.37 \\
\hline
\end{tabular}
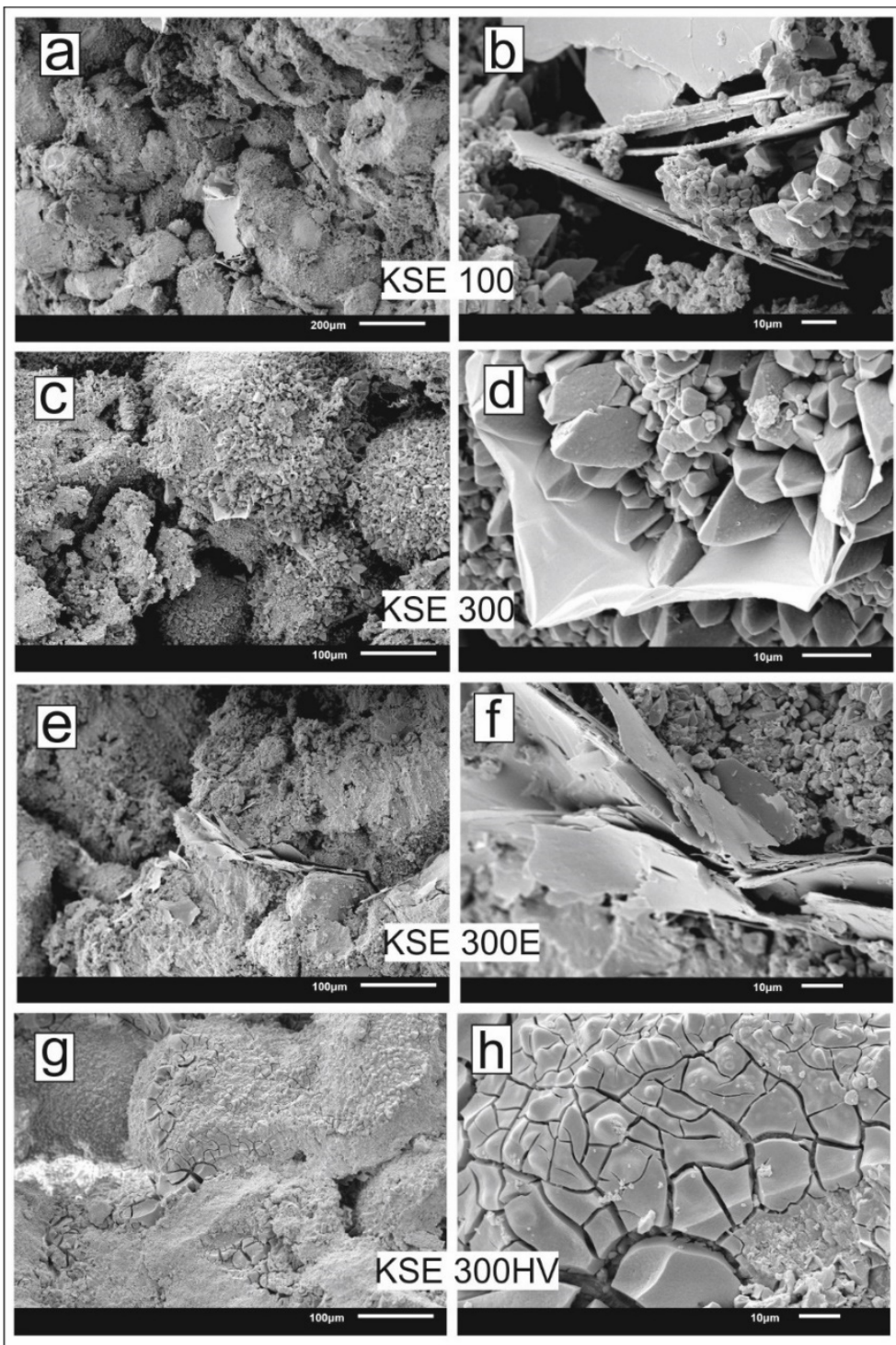

Figure 8. Scanning electron microscopic images of consolidated samples of SM. (a,b) thin plates of KSE 100 partly filling pores; (c,d) pore filling thicker forms of solid silica gel of KSE 300; (e,f) thin curved flakes of KSE 300 E forming elastic bonds between carbonate particles; (g,h) pore filling but not pore occluding consolidant of KSE $300 \mathrm{HV}$ with micro-cracks. 


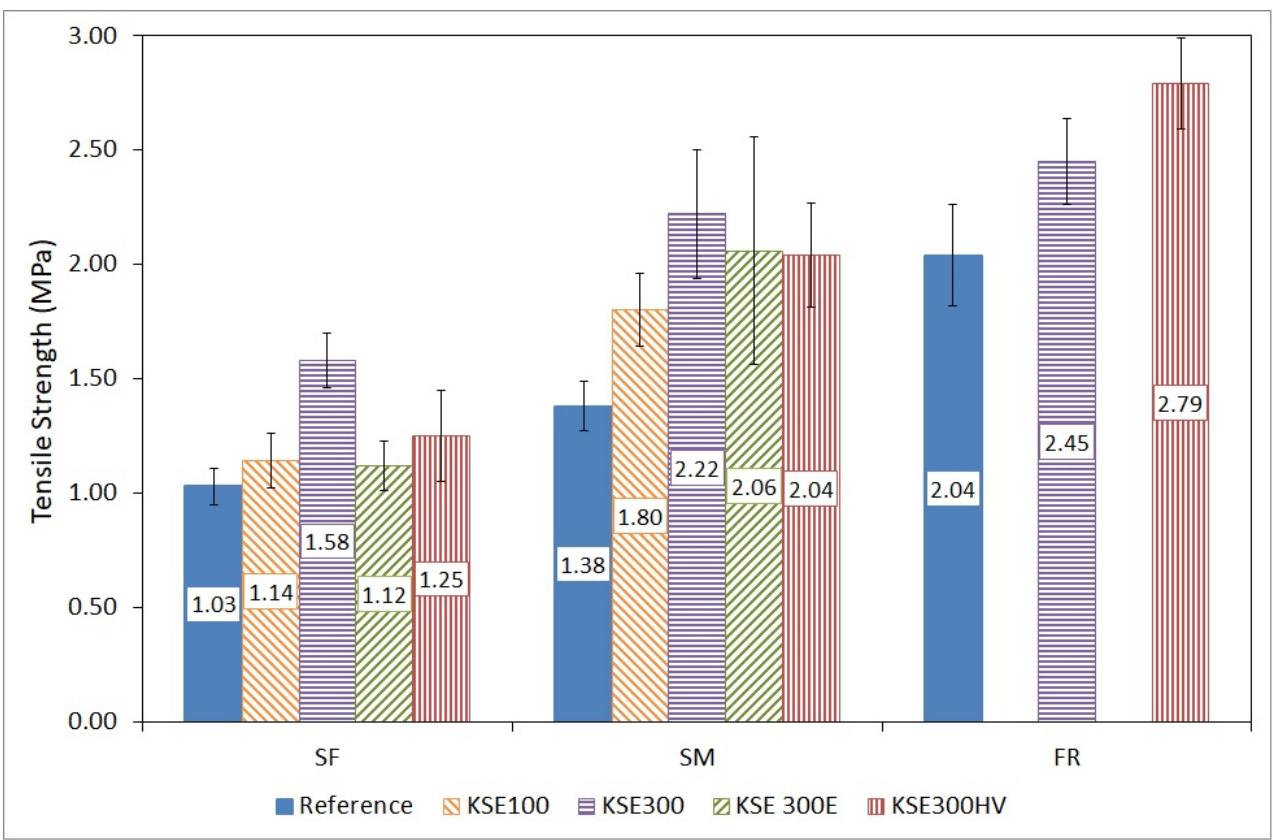

Figure 9. Tensile strength test results of reference samples vs. consolidated samples of SF, SM, and FR porous limestone (blue bars: reference values of the untreated samples, striped bars: treated samples).

\subsection{Durability}

Tensile strength decreased after water saturation and after the ten freeze-thaw cycles. Water saturation reduced fine-grained oolitic limestone (SF) strength by $47 \%$ compared to the reference sample (Figure 10). The tensile strength of water-saturated consolidated samples is also lower than that of the air-dry ones with a reduction of more than $50 \%$ (KSE 100), 44\% (KSE 300), 38\% (KSE 300 E), and 42\% (KSE 300 HV) (Figure 10).

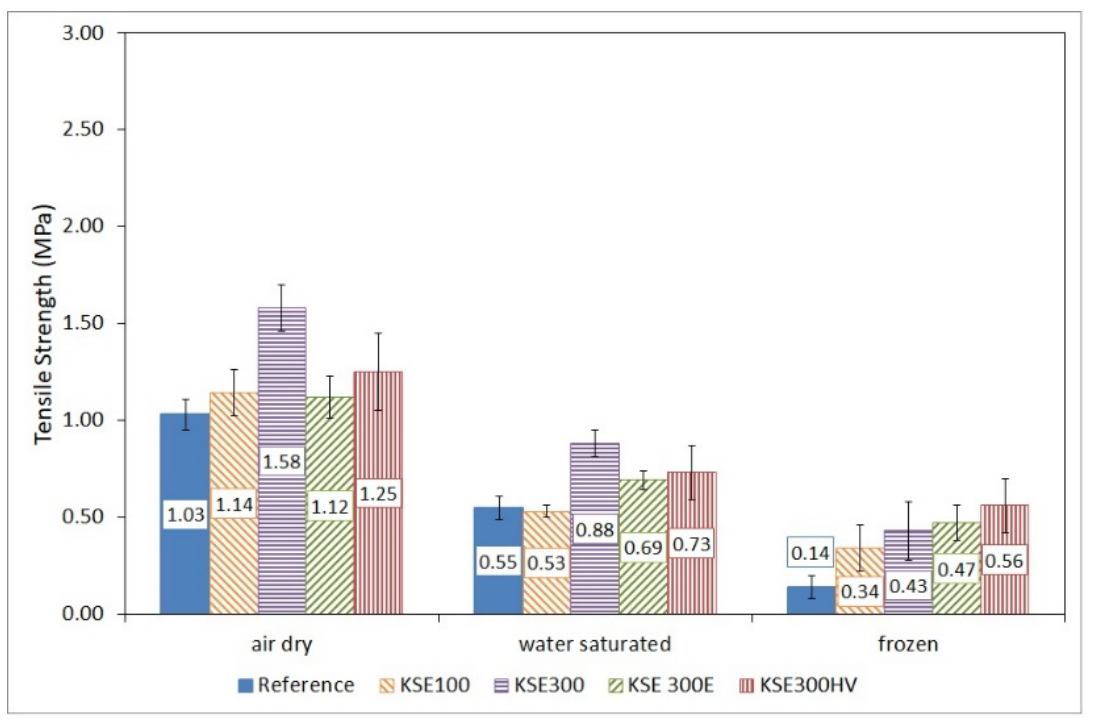

Figure 10. Tensile strength of untreated and treated fine-grained porous limestone from Sóskút (SF) in air dry, water-saturated conditions and after 10 freeze-thaw cycles.

The water saturation reduced the tensile strength of medium-grained limestone (SM) to $72 \%$ of its original values. The consolidated samples also show similar loss of strength (in the order of $30 \%$ ) when air dry and water saturated samples are compared. The reduced strength of the KSE 300 treated water saturated SM is 71\%; the KSE $300 \mathrm{E}$ treated one is $67 \%$, while the KSE $300 \mathrm{HV}$ consolidated SM is $70 \%$ of the air dry reference samples. Like 
SF, the highest reduction in strength of SM was measured due to water saturation at KSE 100 consolidated samples, with a strength loss of $38 \%$ (Figure 11).

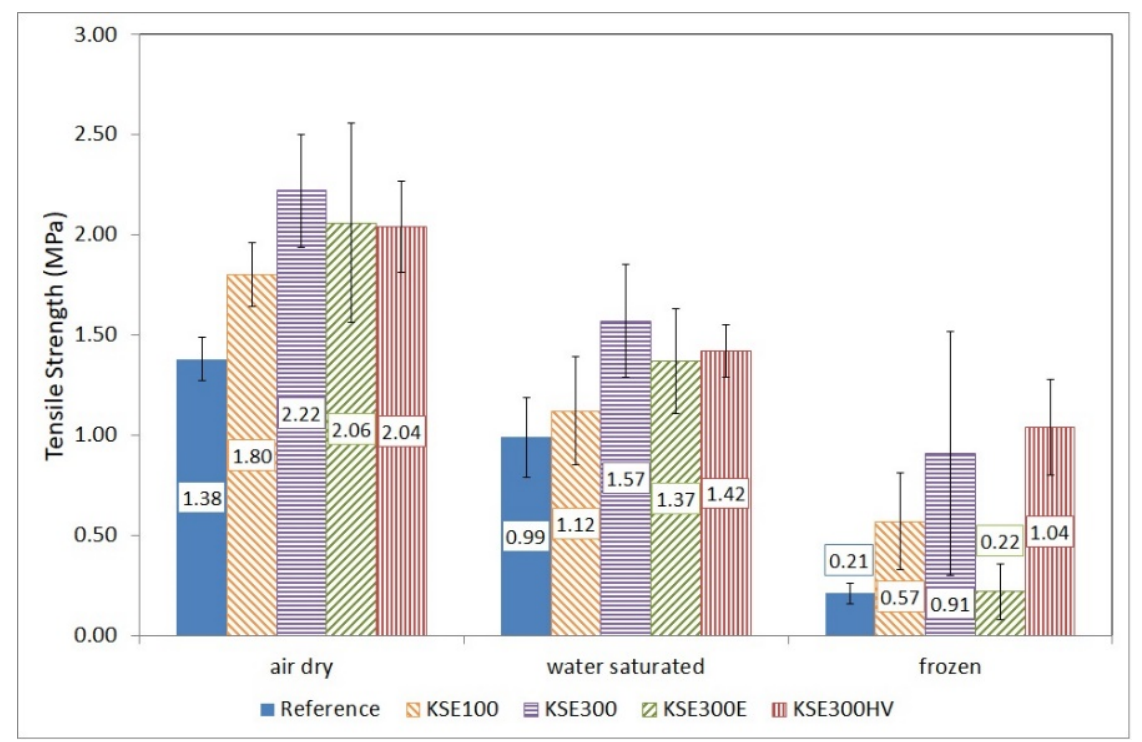

Figure 11. Tensile strength of untreated and treated medium-grained porous limestone from Sóskút (SM) in air dry, water-saturated conditions and after 10 freeze-thaw cycles.

The FR limestone untreated samples have the lowest strength reduction linked to water saturation. The strength of water saturated sample is $76 \%$ compared to the dry reference sample. The consolidation with KSE 300 reduced the strength loss; it is only $82 \%$ for the water saturated consolidated sample compared to the air dry consolidated one. Meanwhile, the water saturation caused a strength loss of $41 \%$ of the KSE $300 \mathrm{HV}$ treated specimens (Figure 12). Freeze-thaw cycles reduced the strength of all studied samples. The loss in the strength of unconsolidated reference samples due to freeze-thaw was not uniform and showed different trends for the studied lithotypes.

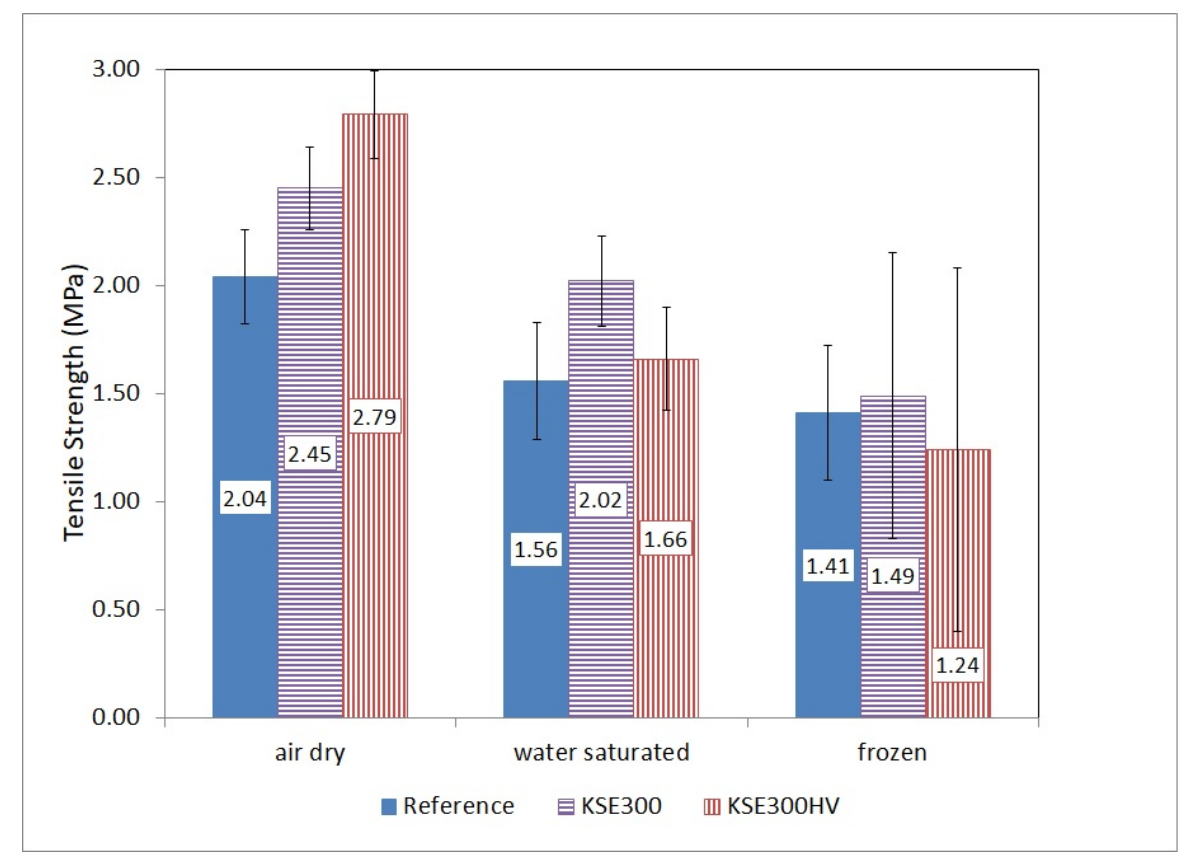

Figure 12. Tensile strength of untreated and treated Fertőrákos limestone (FR) in air dry, watersaturated conditions and after 10 freeze-thaw cycles. 
The strength of the reference fine-grained (SF) and medium-grained (SM) limestone from Sóskút became $25 \%$ and $21 \%$ of the initial water-saturated values after freeze-thaw. The indirect tensile strength of frost-damaged, non-consolidated samples was under $0.25 \mathrm{MPa}$. Fertőrákosi limestone (FR) is less sensitive to frost.

In general, the consolidation increased the durability against frost damage of SF and SM limestone with one exception; the KSE 300 E treated SM samples. The freeze-thaw cycles caused a reduction of the strength of SF limestone samples compared to watersaturated ones to $64 \%, 49 \%, 68 \%$, and to $77 \%$ after the KSE 100, KSE 300, KSE 300 E, and KSE300 HV treatments, respectively (Figure 10).

The reduced strength was 51\% for KSE 100, 58\% for KSE 300 and for 73\% KSE 300 HV treated and frost affected SM specimens (Figure 11). The major loss in strength (one-fourth of the original value) was observed at KSE 300 E treated specimens, where the mean tensile strength reduced to $0.22 \mathrm{MPa}$ compared to $1.37 \mathrm{MPa}$ of water-saturated samples.

Freeze-thaw also reduced the strength of consolidated FR limestone samples. The percentages of strength values of frost damaged vs. water-saturated specimens are: $90 \%$, $74 \%$, and $75 \%$ of reference samples, KSE 300 and KSE 300 HV treated samples, respectively (Figure 12).

The strength loss after 10 freeze-thaw cycles of non-consolidated (reference) and consolidated samples are given in Figure 13. The FR lithotype is less sensitive to frost damage than SF and SM. In general, the consolidants improved the frost resistance of SF and SM, except KSE300E for SM. Despite the consolidation, the tensile strength of frost damaged SF and SM did not reach the tensile strength of the reference FR samples obtained after 10 freeze-thaw cycles.

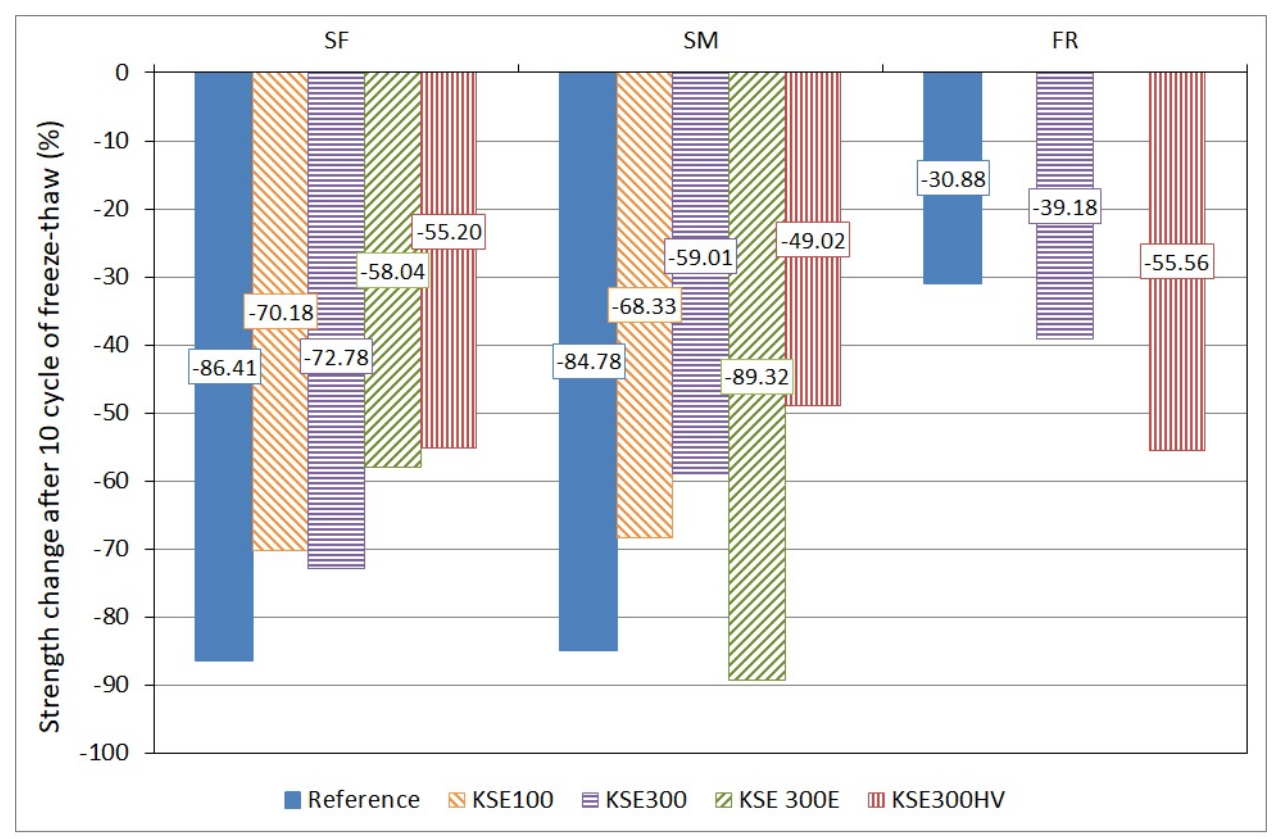

Figure 13. Strength change of untreated and treated porous limestone after 10 freeze-thaw cycles.

There is no significant difference between the resistance against salt attack of consolidated and untreated quarry samples of the FR lithotypes (Figure 14). The consolidation treatment does not increase the durability. On the contrary, at limestones from Sóskút (SF, SM), the treatment with KSE 100 reduced the durability of samples against salt weathering (Figures 15 and 16). The material loss is more significant than that of the untreated samples. The KSE $300 \mathrm{HV}$ treated SF and SM samples performed a little better than the reference samples. The KSE 300 consolidant significantly increased the SM samples' durability (Figure 16), while it only slightly reduced the material loss of SF during salt crystallization cycles (Figure 15). The material loss of KSE 300 treated SM is very low; it is only $8.8 \mathrm{~m} \%$ 
even after 10 salt crystallization cycles (Figure 16). The result of KSE 300E treated SM samples shows an interesting pattern. Up to four salt crystallization cycles, the samples seem to resist against salt attack, but after that, a rapid weight loss begins with an increasing number of salt crystallization cycles, and after eight cycles, the consolidated SM has higher weight loss than the untreated sample (Figure 16).

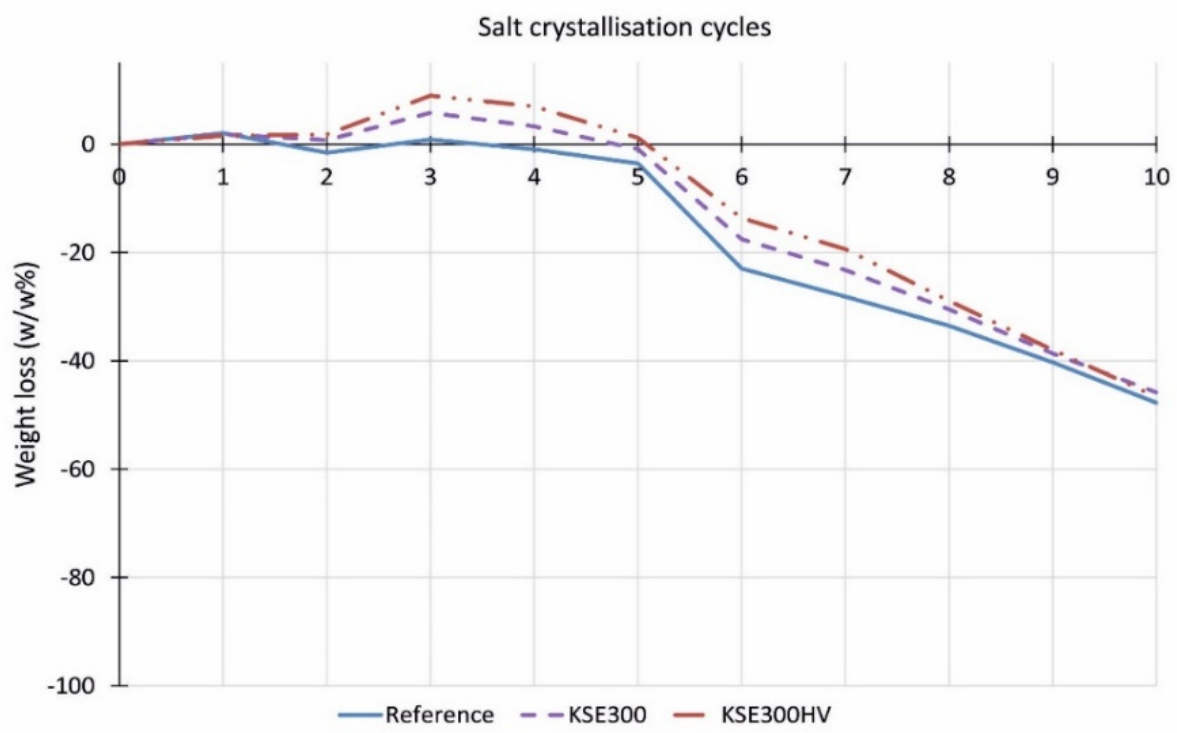

Figure 14. Weight loss of untreated and treated medium-grained porous limestone from Fertőrákos (FR) after salt crystallization cycles.

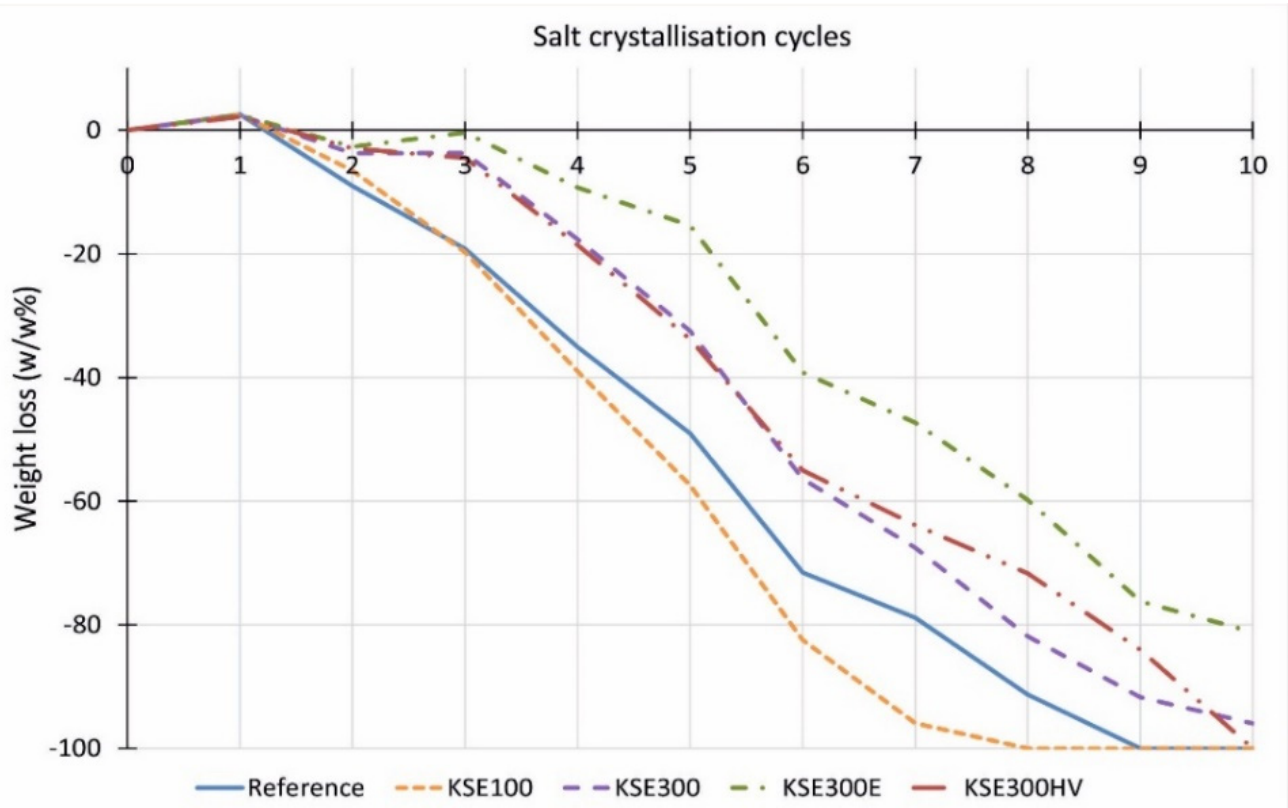

Figure 15. Weight loss of fine-grained porous limestone from Sóskút (SF) after salt crystallization cycles. 


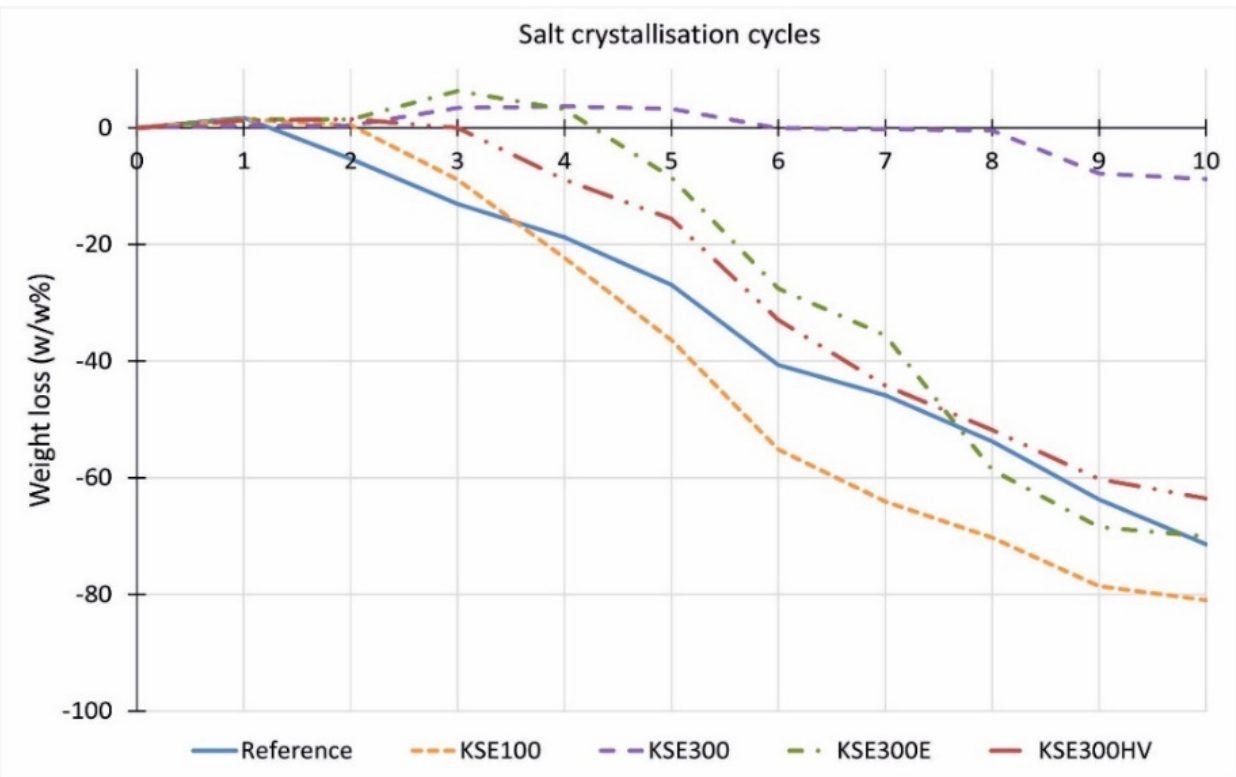

Figure 16. Weight loss of untreated and treated medium-grained porous limestone from Sóskút (SM) after salt crystallization cycles.

\section{Discussion}

The consolidants increased the weight of all samples (Table 3). One would expect a decrease in pore volumes due to consolidation. In general, it is true, but when various consolidants and pore-size ranges are considered other observations were made. The effective pore volume increased or did not change in the treated stone specimens SF KSE 100, SM KSE 100, SM KSE 300, and SM KSE 300 E (Table 4). The amount of pore volume $0.1-10 \mu \mathrm{m}$ was significantly increased for one consolidant KSE $300 \mathrm{HV}$ for SF and SM. It forms bonds between particles but micro-cracks create secondary porosity in this pore range (Figure $8 \mathrm{~g}, \mathrm{~h}$ ). This trend is similar to the one reported on marly limestone due to tetra-ethyl silicate (KSE $300 \mathrm{HV}$ ) consolidation [25].

Comparing the changes between the MIP distributions of the KSE 300 treated and untreated samples, the pore volume increases with treatment in pores of 10-63 $\mu \mathrm{m}$ for SF and SM limestone while the amounts of these pores decreases at FR (Figure 7). In another study [23], micro cracks were generated in Leitha limestone samples using thermal shocks heating up the specimens to $580^{\circ} \mathrm{C}$ for three cycles. The properties of the artificially aged and subsequently KSE 300 treated specimens with the untreated were compared. The pore volume increased between 10-40 microns quite significantly and decreased between 0.1-10 microns. The FR limestone, which is texturally similar to Leitha limestone, did not show the same pore-size distribution change. To the contrary, the amount of pores of 10-63 $\mu \mathrm{m}$ decreased, while the pores of 0.1-10 $\mu \mathrm{m}$ increased after consolidation.

Elastic silica-acid ester (KSE 300E) forms bonds between carbonate particles (Figure 8e,f) but it did not cause a major change in the pore-size distribution of the consolidated limestone (Table 4, Figure 7). KSE 100 forms thin plates in the pores (Figure 8a,b) and it reduces the pore volume of pores less than $10 \mu \mathrm{m}$ and increased the pores larger than $10 \mu \mathrm{m}$ (Table 4, Figure 7) of SM. Reference samples of SF and KSE 100 consolidated variety of SF have similar pore-size distribution.

The splitting tensile strength results of our study are lower than the ones published for similar Miocene limestone the Leitha limestone [23]. The strength of SF is $1.03 \mathrm{MPa}$, and 1.38 MPa of SM, while that of the FR is $2.04 \mathrm{MPa}$. The sound stone of St. Margarethen has higher tensile-strength $3.3 \mathrm{MPa}$. After heat treatment, the St. Margarethen stone has a reduced strength of 1.2MPa. Consolidation with KSE 300 increased this value to $1.7 \mathrm{MPa}$. This means a $141 \%$ increase in strength due to the consolidation which is more than our result with $120 \%$ of KSE300 consolidated FR (Figure 9, Table 5). 
Salt crystallization of sodium sulphate in sound stones after 10 cycles caused a weight loss of SF 70-100 w/w\% (Figure 15), SM 60-80 w/w\% (except KSE 300) (Figure 16), and FR $45-50 \%$ in this study (Figure 14), while a consolidated Italian high porous limestone (Modica stone) had a weight loss of $60 \mathrm{w} / \mathrm{w} \%$ after 15 cycles [24]. It has to be noted that they have salt-treated the samples first, and after consolidation, additional salt crystallization tests were performed in order to assess the resistance of the treated stone to further salt crystallization. In addition, the treating process was much longer (15 days) [24] than in our study (10 min). They have found that the effect of the consolidants was very low if the number of ageing cycles before treatment was over one salt crystallization cycle. However, good results were measured just with nanoLime, and tetra-ethyl silicate did not prove suitable for consolidation of Modica stones.

Comparing the results of salt crystallization cycle durability tests and freeze-thaw cycled durability of the studied three limestone types, it is clear that there are different trends. Namely, the consolidant that performs well in terms of freeze-thaw durability (Figure 13) does not increase the durability of the stone against salt crystallization cycles (Figures 14-16). The weight loss is the lowest at FR limestone when the reference samples are compared (Figure 14). The same lithotype (FR) shows the lowest reduction in tensile strength after freeze-thaw (Figure 13). Comparing the performance of consolidants, it seems that no 'universal' consolidant exists. The KSE 300 reduced the weight loss and the tensile strength decrease of SM and FR, while it seems less efficient at SF. The KSE $300 \mathrm{E}$ helped to maintain the weight of SF during salt crystallization cycles, but it did not hamper the fall of the tensile strength (Figure 13). KSE $300 \mathrm{HV}$ performed the best in terms of strength loss for SF and SM against frost action (Figure 13), while it did not consolidate FR against salt attack (Figure 14). The resistance against sulphate crystallization cycles seems to correlate better with the strength of water saturated samples (SM) (Figure 11), and it seems that capillary water absorption (SF) (Figure 5) also indicates the salt durability of lithotypes from Sóskút.

High capillary water absorption of tested Hungarian limestone could also mark the sensitivity to salt attack, namely, high water absorption of SF (Figure 5) compared to the water absorption of SM (Figure 6) could predict durability against salt crystallization. The effect of consolidation on the water saturated samples follows the same pattern as that of the dry samples. The only exception is the KSE $300 \mathrm{HV}$ treated FR limestone samples. The effect of consolidation on strength, considering the freeze-thaw resistance compared to air dry and water-saturated samples have very distinct trends. KSE 300 consolidant performs the best at SF and SM samples when the dry and water-saturated samples are compared. On the other hand, the KSE 300 HV seems to increase the durability, namely, the strength, the most when the consolidated samples are subjected to freeze-thaw cycles. Conversely, KSE $300 \mathrm{HV}$ has an adverse effect of freeze-thaw durability of FR limestone.

Our tests suggest that an initial increase in strength linked to consolidation does not forecast increased durability against freeze-thaw and salt crystallization. The tensile strength of KSE $300 \mathrm{E}$ and KSE $300 \mathrm{HV}$ consolidated SM equally shows a gain of 50\% compared to the reference sample; meanwhile, the former seems inefficient against the frost damage, while the latter increased the frost durability of SM (Figure 11). These two consolidants improved the resistance against salt crystallization of SM up to a few cycles (Figure 16). The effect of consolidants on SF is different. The samples treated with KSE 300 E showed the smallest increase in tensile strength (Figure 9, Table $5+9 \%$ ), but it became the most efficient consolidant against salt weathering (Figure 15) and the secondbest against frost of SF limestone (Figure 10). The capillary water absorption of KSE 100 treated SF (Figure 5) and SM (Figure 6) show higher values which are also clearly reflected in the reduced strength of water saturated samples, namely the loss is in tensile strength is $53 \%$ and $28 \%$, respectively (Figures 10 and 11 ). The high capillary water absorption marks the porous limestone's poor performance, as was previously suggested $[13,23]$. The KSE 300 and KSE 300 HV increased third lithotype strength by 20\% and 30\% (Figure 9, 
Table 5), but none of these consolidants made the consolidated FR stone resistant against frost or salt crystallization.

Our study also suggests that silica acid esters are not fully compatible with limestone and cannot be used universally [23]. Indeed, these compounds, the ethyl silicates, were first applied for sandstone, and the use of this consolidant for limestone became common practice later [26]. However, the limitations of its application were also unraveled [23,26]. It has been described that the efficiency of consolidation of sandstone with KSE depends on the cement material of the quartz sandstones and also on the pore-size distribution [38]. According to this study [38], all KSE products decreased the pore diameter, the total porosity and also reduced the connectivity of pores of clay, silica or carbonate cemented German sandstones. The strength test of the latter one indicates that the binding of KSE 100 consolidants to carbonates is less efficient than the binding of KSE 300 to the silica cemented sandstone, providing a lower strength increase. Our study partly confirms this since KSE 100 caused the smallest strength increase to SM, however for the other lithotype for the fine-grained limestone (SF), the tensile strength increase after KSE 300 E treatment was less than consolidation with KSE 100 (Figure 9). These discrepancies indicate that textural characteristics also control the efficacy of consolidation, as it was previously suggested [23]. We have also observed (Figure 8) that micro-cracks appear in the consolidant [23,27], but in one previous work [38], the cracks were more prone in high gel deposition rate consolidant in KSE 510. Depending on the gel deposition rate and the deposited amount of gel in sandstone pores, the strength increase was different for KSE 100, KSE 300, and KSE 510 [38]. Modified silica acid esters seem to perform well on low strength sandstone, too [28]. This research on porous limestone consolidation is in line with previous works [23]. It seems that the increase in strength induced by consolidation is controlled by the micro-fabric and pore-size distribution of the porous limestone and also depends on gel deposition rate of the consolidants. There is a mechanical strength gain of the tested porous limestone due to silica acid ester consolidants, similarly to sandstones [38]. Nevertheless, in a previous work comparing the consolidation of limestone and sandstone [23], it was clearly explained that the different micro-fabrics can simply downsize the better chemical compatibility (Si-O-Si bonds) of silica-based consolidants and sandstone and control the efficacy of treatment. Our research confirms this statement since micro-fabric controls the efficacy of consolidation of the studied porous limestone (Figure 9). It also influences the durability of consolidated stones against freeze-thaw (Figure 13) and salt weathering (Figures 14-16), suggesting that taking into account all factors SM performs the best. As emphasized previously [23], there is no uniform consolidant that works for all lithotypes, and our findings agree with this statement.

\section{Conclusions}

The texture of the three lithotypes is different, and this difference is reflected in their tensile strength. The silica acid esters consolidants increased the strength of the lithotypes but this improvement is not long-lasting since when the stones are subjected to freeze-thaw or salt crystallization, a rapid loss of strength was recorded. The tests have shown that the microfabric of the porous limestone strongly influences the efficiency of stone consolidants.

The consolidation of SF and SM lithotypes with silica acid ester increases the durability with the exceptions of SM KSE 300 E (freeze-thaw), SF and SM KSE 100 (sodium sulphate). To the contrary, the durability of FR against freeze-thaw and salt crystallization cycles was not improved by the consolidation with the four tested silica acid esters.

These compounds were developed for sandstone and silicate rocks. However, when it is necessary to use silica acid esters for SF and SM porous limestones, the best results are obtained using KSE $300 \mathrm{HV}$ in terms of strength loss due to water saturation and freeze-thaw and durability against salt crystallization, but for the latter one its efficacy is limited. KSE $300 \mathrm{HV}$ forms the most effective binding between particles according to SEM images and the largest amount of solid silica in the pores. For the third tested lithotype Fertőrákos limestone (FR), the consolidation with any silica acid esters is not suggested 
since the two tested consolidants slightly increase the strength but it does not increase the durability against frost and salt crystallization.

Our experiments suggest that it is necessary to perform laboratory tests to assess the durability against frost and salt crystallization damage since the initial increase in strength after consolidation could be misleading. It does not reflect the durability and the effect of these extrinsic factors.

Author Contributions: Writing—original draft preparation Z.P., N.R.-B., Á.T.; Experimental set up and experiments Z.P. and N.R.-B. Conceptualization, methodology, and investigation with data analysis Z.P., N.R.-B., and Á.T. Editing and reviewing Z.P., N.R.-B., and Á.T., Funding acquisition, Á.T. All authors have read and agreed to the published version of the manuscript.

Funding: The financial support of National Research, Development and Innovation (NKFI) Fund (project nos. K 116532 and NN 127023) is acknowledged.

Institutional Review Board Statement: Not applicable.

Data Availability Statement: Not applicable.

Acknowledgments: The authors are grateful to Orsolya Farkas for the support to MIP analyses. We are grateful for the use of the SEM facility at the University of Cyprus, with the help of Ioannis Rigopoulos and Ioannis Ioannou.

Conflicts of Interest: The authors declare no conflict of interest.

\section{References}

1. Török, Á. Oolitic limestone in a polluted atmospheric environment in Budapest: Weathering phenomena and alterations in physical properties. In Natural Stones, Weathering Phenomena, Conservation Strategies and Case Studies; Siegesmund, S., Weiss, T.S., Vollbrecht, A., Eds.; Geological Society Special Publications: London, UK, 2002; Volume 205, pp. 363-379. [CrossRef]

2. Török, Á.; Rozgonyi, N. Mineralogy and morphology of salt crusts on porous limestone in urban environment. Environ. Geol. 2004, 46, 323-339.

3. Fehér, K.; Halmos, B. Remarks on the Proportions and Dimensions Used in the Design of the Medieval Church of Zsámbék. Period. Polytech. Arch. 2019, 50, 97-114. [CrossRef]

4. Török, Á.; Rozgonyi, N.; Prikryl, R.; Prikrylová, J. Leithakalk: The ornamental and building stone of Central Europe, an over-view. In Dimension Stone; Prikryl, R., Ed.; Balkema: Rotterdam, The Netherlands, 2004; pp. $89-93$.

5. Bednarik, M.; Moshammer, B.; Heinrich, M.; Holzer, R.; Laho, M.; Rabeder, J.; Uhlir, C.; Unterwurzacher, M. Engineering geological properties of Leitha Limestone from historical quarries in Burgenland and Styria, Austria. Eng. Geol. 2014, 176, 66-78. [CrossRef]

6. Přikryl, R. Durability assessment of natural stone. Q. J. Eng. Geol. Hydrogeol. 2013, 46, 377-390. [CrossRef]

7. Přikryl, R.; Přikrylová, J. Leithakalk limestones in the Lednice-Valtice area (southest Moravia, Czech Republic): Their occurrences and properties. In Dimension Stone; Prikryl, R., Ed.; Balkema: Rotterdam, The Netherlands, 2004; pp. 149-156.

8. De Kock, T.; Van Stappen, J.; Fronteau, G.; Boone, M.; De Boever, W.; Dagrain, F.; Silversmit, G.; Vincze, L.; Cnudde, V. Laminar gypsum crust on lede stone: Microspatial characterization and laboratory acid weathering. Talanta 2017, 162, 193-202. [CrossRef] [PubMed]

9. Cassar, J.A. Deterioration of the Globigerina limestone of the Maltese Islands. In Natural Stones, Weathering Phenomena, Conservation Strategies and Case Studies; Siegesmund, S., Weiss, T.S., Vollbrecht, A., Eds.; Geological Society Special Publications: London, UK, 2002; Volume 205, pp. 33-49. [CrossRef]

10. Pappalardo, G.; Mineo, S.; Monaco, C. Geotechnical characterization of limestones employed for the reconstruction of a UNESCO world heritage Baroque monument in southeastern Sicily (Italy). Eng. Geol. 2016, 212, 86-97. [CrossRef]

11. Beck, K.; Al-Mukhtar, M. Formulation and characterization of an appropriate lime-based mortar for use with a porous limestone. Environ. Geol. 2008, 56, 715-727. [CrossRef]

12. Hassine, M.A.; Beck, K.; Brunetaud, X.; Al-Mukhtar, M. Strain measurements during capillary water infiltration in porous limestones. Constr. Build. Mater. 2018, 175, 439-447. [CrossRef]

13. Benavente, D.; del Cura, M.A.G.; Fort, R.; Ordóñez, S. Durability estimation of porous building stones from pore structure and strength. Eng. Geol. 2004, 74, 113-127. [CrossRef]

14. Vasarhelyi, B. Statistical analysis of the influence of water content on the strength of the Miocene Limestone. Rock Mech. Rock Eng. 2005, 38, 69-76. [CrossRef]

15. Török, Ákos; Ficsor, A.; Davarpanah, M.; Vásárhelyi, B. Comparison of mechanical properties of dry, saturated and frozen porous rocks. In Proceedings of the IAEG/AEG Annual Meeting, San Francisco, CA, USA, 17-21 September 2018; Volume 6, pp. 113-118. [CrossRef] 
16. Pápay, Z.; Török, Á. Effect of Thermal and Freeze-thaw Stress on the Mechanical Properties of Porous Limestone. Period. Polytech. Civ. Eng. 2018, 62, 423-428. [CrossRef]

17. Vásárhelyi, B.; Davarpanah, S.M. Influence of Water Content on the Mechanical Parameters of the Intact Rock and Rock Mass. Period. Polytech. Civ. Eng. 2018, 62, 1060-1066. [CrossRef]

18. Yu, S.; Oguchi, C.T. Role of pore size distribution in salt uptake, damage, and predicting salt susceptibility of eight types of Japanese building stones. Eng. Geol. 2010, 115, 226-236. [CrossRef]

19. La Russa, M.F.; Ruffolo, S.A.; Belfiore, C.M.; Aloise, P.; Randazzo, L.; Rovella, N.; Pezzino, A.; Montana, G. Study of the effects of salt crystallization on degradation of limestone rocks. Period. Miner. 2013, 82, 113-127.

20. Flatt, R.; Mohamed, N.A.; Caruso, F.; Derluyn, H.; Desarnaud, J.; Lubelli, B.; Marzal, R.M.E.; Pel, L.; Rodriguez-Navarro, C.; Scherer, G.W.; et al. Predicting salt damage in practice: A theoretical insight into laboratory tests. RILEM Tech. Lett. 2017, 2, 108-118. [CrossRef]

21. Molina, E.; Cultrone, G.; Sebastián, E.; Alonso, F.; Carrizo, L.; Gisbert, J.; Buj, O. The pore system of sedimentary rocks as a key factor in the durability of building materials. Eng. Geol. 2011, 118, 110-121. [CrossRef]

22. Cárdenes, V.; Mateos, F.J.; Fernández-Lorenzo, S. Analysis of the correlations between freeze-thaw and salt crystallization tests. Environ. Earth Sci. 2013, 71, 1123-1134. [CrossRef]

23. Ban, M.; Mascha, E.; Weber, J.; Rohatsch, A.; Rodrigues, J.D. Efficiency and Compatibility of Selected Alkoxysilanes on Porous Carbonate and Silicate Stones. Materials 2019, 12, 156. [CrossRef] [PubMed]

24. Ruffolo, S.A.; La Russa, M.F.; Ricca, M.; Belfiore, C.M.; Macchia, A.; Comite, V.; Pezzino, A.; Crisci, G.M. New insights on the consolidation of salt weathered limestone: The case study of Modica stone. Bull. Eng. Geol. Environ. 2017, 76, 11-20. [CrossRef]

25. Karatasios, I.; Michalopoulou, A.; Amenta, M.; Kilikoglou, V. Modification of water transport properties of porous building stones caused by polymerization of silicon-based consolidation products. Pure Appl. Chem. 2017, 89, 1673-1684. [CrossRef]

26. Wheeler, G.; Goins, E.S. Alkoxysilanes and the Consolidation of Stone; The Getty Conservation Institute: Los Angeles, CA, USA, 2005; ISBN 9780892368150.

27. Remzova, M.; Šašek, P.; Frankeová, D.; Slížková, Z.; Rathousky, J. Effect of modified ethylsilicate consolidants on the mechanical properties of sandstone. Constr. Build. Mater. 2016, 112, 674-681. [CrossRef]

28. Remzova, M.; Zouzelka, R.; Lukes, J.; Rathousky, J. Potential of Advanced Consolidants for the Application on Sandstone. Appl. Sci. 2019, 9, 5252. [CrossRef]

29. Stück, H.; Forgó, L.Z.; Rüdrich, J.; Siegesmund, S.; Török, Á. The behaviour of consolidated volcanic tuffs: Weathering mechanisms under simulated laboratory conditions. Environ. Geol. 2008, 56, 699-713. [CrossRef]

30. Dei, L.; Salvadori, B. Nanotechnology in cultural heritage conservation: Nanometric slaked lime saves architectonic and artistic surfaces from decay. J. Cult. Herit. 2006, 7, 110-115. [CrossRef]

31. Ruffolo, S.A.; La Russa, M.F.; Aloise, P.; Belfiore, C.M.; Macchia, A.; Pezzino, A.; Crisci, G.M. Efficacy of nanolime in restoration procedures of salt weathered limestone rock. Appl. Phys. A 2014, 114, 753-758. [CrossRef]

32. Tzavellos, S.; Pesce, G.L.; Wu, Y.; Henry, A.; Robson, S.; Ball, R.J. Effectiveness of Nanolime as a Stone Consolidant: A 4-Year Study of Six Common UK Limestones. Materials 2019, 12, 2673. [CrossRef]

33. Török, Á.; Vásárhelyi, B. The influence of fabric and water content on selected rock mechanical parameters of travertine, examples from Hungary. Eng. Geol. 2010, 115, 237-245. [CrossRef]

34. Çelik, M.Y. Water absorption and P-wave velocity changes during freeze-thaw weathering process of crosscut travertine rocks. Environ. Earth Sci. 2017, 76. [CrossRef]

35. Gökçe, M.V.; Ince, I.; Fener, M.; Taşkıran, T.; Kayabali, K. The effects of freeze-thaw (F-T) cycles on the Gödene travertine used in historical structures in Konya (Turkey). Cold Reg. Sci. Technol. 2016, 127, 65-75. [CrossRef]

36. Bozda $\breve{g}$, A.; Ince, I.; Bozdağ, A.; Hatır, M.E.; Tosunlar, M.B.; Korkanç, M. An assessment of deterioration in cultural heritage: The unique case of Eflatunpinar Hittite Water Monument in Konya, Turkey. Bull. Eng. Geol. Environ. 2020, 79, 1185-1197. [CrossRef]

37. Török, Á. Hungarian travertine: Weathering forms and durability. In Heritage Weathering and Conservation; Fort, R., de Buego, A.M., Gomez-Heras, M., Vazquez-Calvo, C., Eds.; Taylor \& Francis: London, UK; Balkema: Rotterdam, The Netherlands, 2006; Volume 1, pp. 199-204.

38. Braun, F.; Orlowsky, J. Effect of Different Silicic Acid Ester on the Properties of Sandstones with Varying Binders. Restor. Build. Monum. 2017, 23. [CrossRef] 